\title{
Questões de Michel Foucault à Revista Hérodote
}

Michel Foucault

\section{Questões de Michel Foucault à Hérodote ${ }^{1}$}

Michel Foucault, cujo Hérodote publicou uma longa entrevista em seu primeiro número $^{2}$, gentilmente nos enviou essas questões - o que ele considera como uma nova etapa na direção de uma colaboração. Fizemos circular sua carta entre os membros do grupo de discussão. Por falta de tempo, vários entre eles não responderam a tempo para este número. Publicaremos, portanto, o conjunto dos comentários no $\mathrm{n}^{\mathrm{o}} 5$ que será consagrado às questões de estratégia ${ }^{3}$.

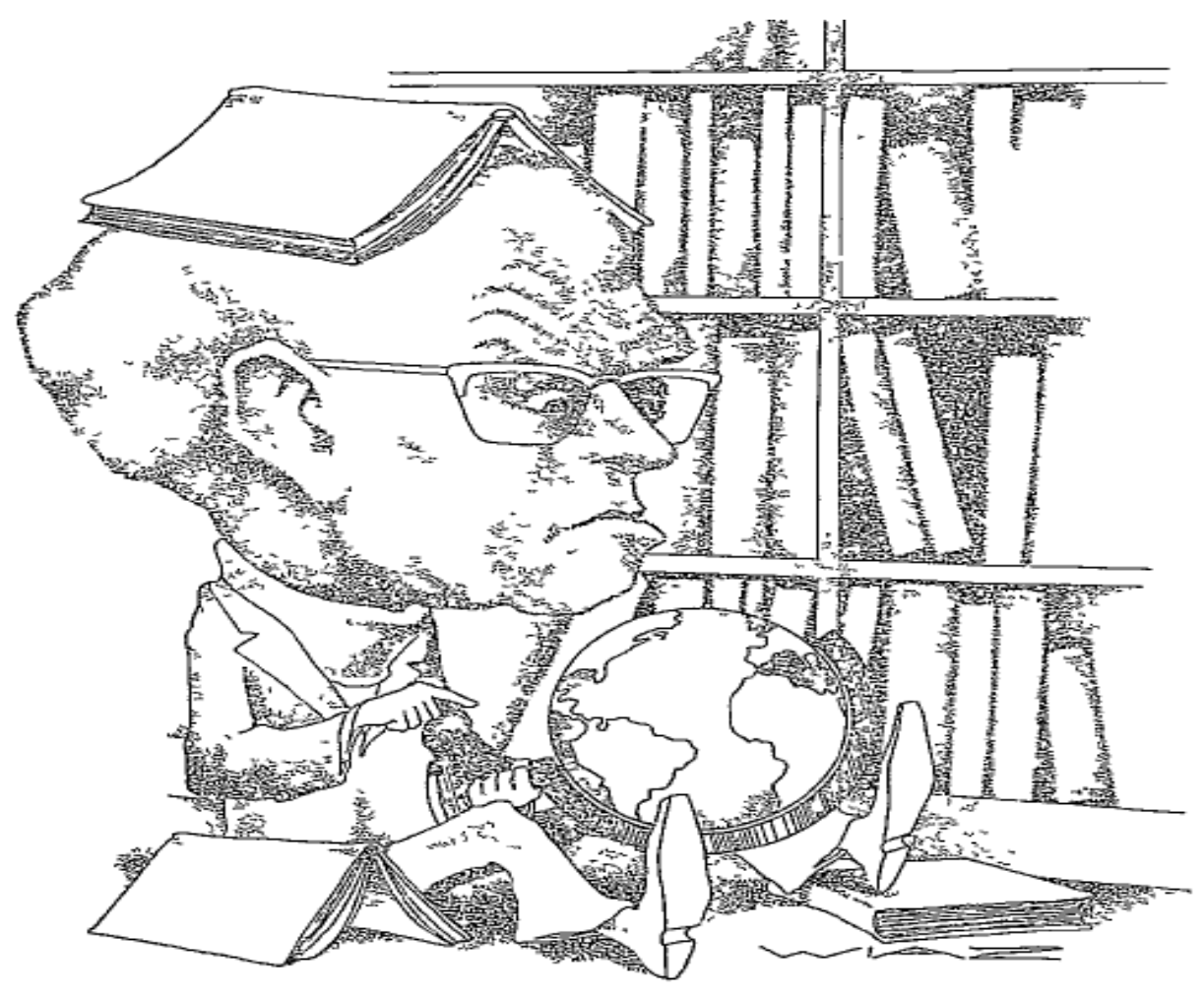

\footnotetext{
${ }^{1}$ FOUCAULT, Michel. Des questions de Michel Foucault à Hérodote. In: Hérodote - stratégies géographie - idéologie. Revue trimestriel, Paris: François Maspero, $\mathrm{n}^{\mathrm{o}} 3$, pp. 09-11, juillet-septembre, 1976. Todos os grifos são conforme o original (N. T.). Tradução de Marquessuel Dantas de Souza.

${ }^{2}$ Questions à Michel Foucault sur La géographie. In: Hérodote - stratégies - géographie - idéologie. Revue trimestriel, Paris: François Maspero, no 1, pp. 71-85, janvier-mars, 1976. Existe uma tradução brasileira. FOUCAULT, Michel. Sobre a Geografia. In: Microfísica do Poder. (1 $1^{\mathrm{a}}$ edição de 1979). 10 edição. (Organização e tradução de Roberto Machado). Rio de Janeiro: Graal, 1992. 296p.

${ }^{3}$ Em realidade, os comentários referidos foram publicados no $\mathrm{n}^{\circ}$ 6. Confira Des réponses aux questions de Michel Foucault. In: Hérodote - stratégies - géographie - idéologie. Revue trimestriel, Paris: François Maspero, nº 6, avril-juin, 1977.
} 
Essas não são questões que vos peço a partir de um conhecimento que gostaria. São interrogações que me pergunto, e que vos endereço, pensando que vocês são, sem dúvida, mais avançados do que eu neste caminho.

1. A noção de estratégia é essencial quando queremos realizar a análise do conhecimento e de suas relações com o poder. Ela implica, necessariamente, que através do conhecimento em questão se faça a guerra?

A estratégia não permite analisar as relações de poder como técnica de dominação?

Caso contrário, qual a extensão que vocês dão à noção de estratégia?

2. Se compreendi bem, vocês buscam constituí-la um conhecimento dos espaços. É importante para vocês constituí-la como ciência?

Ou vocês aceitariam em dizer que o corte que marca o limiar da ciência é apenas uma maneira de desqualificar certos conhecimentos ou de fazê-lo escapar ao exame?

A partilha entre a ciência e o conhecimento não científico é um efeito de poder ligado à institucionalização dos conhecimentos na Universidade, nos centros de pesquisas, etc.

3. Parece-me que vocês vinculam a análise do espaço ou dos espaços menos produção e "recursos" que ao exercício do poder.

Vocês podem esboçar o que entendem por poder? (Por relação ao Estado e aos seus aparelhos, por relação à dominação de classe).

Ou vocês consideram que a análise do poder, seus mecanismos, seu campo de ação ainda está em seu princípio e é muito cedo para dar definições gerais?

Em particular, pensam que podemos responder a questão: quem tem o poder?

\begin{tabular}{|l|l|l|l|l|}
\hline Qevista Dialectus & Ano 4 & n. 11 & Agosto - Dezembro 2017 & p. $327-329$ \\
\hline
\end{tabular}


Vocês pensam que é possível fazer uma geografia - ou, segundo as escalas das geografias - da medicina (não das doenças, mas das implantações médicas com sua zona de intervenção e sua modalidade de ação)?

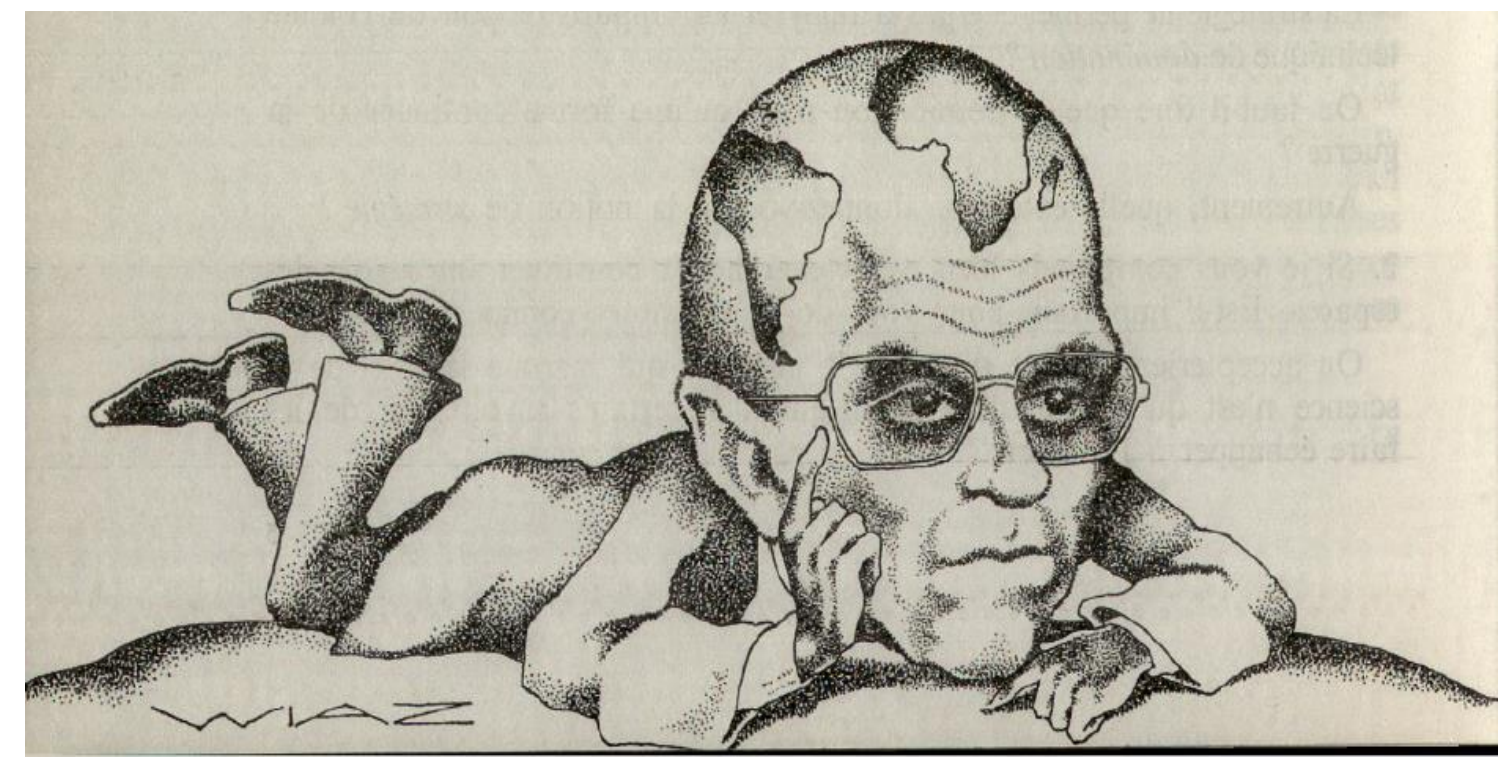

Ambas as ilustrações de Michel Foucault aqui expostas foram coletadas do $n^{\circ} 1$ (1976) e do $n^{\circ} 6$ (1977), respectivamente, da revista Hérodote.

\begin{tabular}{|l|l|l|l|l|}
\hline Q Povista Dialectus & Ano 4 & n. 11 & Agosto - Dezembro 2017 & p. $327-329$ \\
\hline
\end{tabular}

